\title{
Discursos, interlocuções e prática pedagógica no ensino da criança com paralisia cerebral
}

\author{
Marco Antonio Melo Franco ${ }^{1}$ \\ Leonor Bezerra Guerra ${ }^{2}$ \\ Alysson Massote Carvalho
}

\begin{abstract}
Resumo
O estudo investigou como a interlocução entre os campos da Saúde e da Educação podem influenciar na elaboração e reelaboração de práticas pedagógicas no ensino da criança com paralisia cerebral. Trata-se de um estudo qualitativo realizado ao longo do período de um ano letivo. Participaram oito crianças com paralisia cerebral, com idades entre 6 e 12 anos, inseridas no Ensino Fundamental I em escolas regulares e 17 educadores. Foram realizadas entrevista semiestruturadas, com os educadores, no início e final do ano letivo e acompanhamento escolar em períodos bimestrais ou trimestrais. Como resultados, identificou-se que os educadores desconheciam as causas e repercussões da paralisia cerebral na vida acadêmica dos alunos; as práticas pedagógicas eram intuitivas sem direcionamento específico conforme cada comprometimento. Foi observado que a partir das interlocuções, entre os campos de conhecimento envolvidos, as práticas pedagógicas foram reelaboradas, favorecendo a aprendizagem dos alunos.
\end{abstract}

Palavras-Chave: interlocuções; saúde e educação; paralisia cerebral; prática pedagógica.

\footnotetext{
1 Doutor em Ciências da Saúde, com ênfase em Saúde da criança e do adolescente pela Faculdade de Medicina da Universidade Federal de Minas Gerais. Professor do Programa de Pos-Graduação em ensino de Ciências/ ICEB/UFOP. mamf.franco@gmail.com

2 Doutora em Biologia Celular pela UFMG Universidade Federal de Minas Gerais. Professor de Neuroanatomia no Programa de Pós-Graduação em Neurociências do ICB/UFMG.

leonorguerra@gmail.com

3 Doutor em Psicologia pela Universidade de São Paulo. Professor do PPG em Ciências da Saúde da Faculdade de Medicina/UFMG. diretorgeral@gammon.br
} 


\title{
Discourse, interlocutions and pedagogic practice in the teaching of child with cerebral palsy
}

\begin{abstract}
The present study has investigated the way the interlocution among health and education fields may influence the elaboration and over elaboration of pedagogic practices in the teaching of a cerebral palsy child. This is a qualitative study conducted along a school year. Participated eight cerebral palsy children, ages between six and twelve enrolled within primary regular schools and seventeen educators. Were conducted semi-structured interview in the beginning and at the end of school year and school follow up in periods bimonthly or quarterly. As a final result it was observed that the educators: had no knowledge of causes and repercussions of brain palsy in the academic life of the students and that pedagogic practices were intuitive with no specific direction according to each damage. It was also noticed that starting after the interlocutions among the involved knowledge fields, the pedagogic practices were over elaborated favouring students apprenticeship.
\end{abstract}

Keywords: interlocutions; health and education; cerebral palsy; pedagogical practices.

\section{Introdução}

Temas como fracasso escolar, exclusão e inclusão social e escolar, classes especiais e regulares e discurso médico, entre outros, têm orientado as investigações a respeito das práticas educacionais, contribuindo para a composição de um corpus teórico. No presente estudo, o discurso médico, a sua produção e os seus efeitos no discurso e nas práticas pedagógicas escolares, mantendo o foco no processo de ensino-aprendizagem de crianças com paralisia cerebral inseridas no modelo regular de escolarização, constituiu a referência de investigação.

Observa-se que as formas de justificar o não aprender das crianças com paralisia cerebral se assemelham à de outros alunos que apresentam 
dificuldades para a aprendizagem não identificadas pela escola. O olhar colocado sobre a aparência física do aluno e o laudo médico costumam ser os instrumentos mais utilizados. Tal perspectiva nos leva a refletir sobre algumas questões, como, o pseudo-olhar "clínico" do professor seria uma maneira fácil e ágil de resolver uma situação incômoda? Seria esse um retrato do seu desconhecimento e uma evidência da necessidade de se rediscutir a formação docente e as condições de trabalho desse educador? Pode o diagnóstico médico ser um instrumento usado para a exclusão ou a inclusão dos alunos? Ao aluno com deficiência, pode ser negado o direito de participar do processo de escolarização regular a partir de seu diagnóstico e da interpretação e do uso que se faz dele? Como os diferentes discursos, particularmente, o discurso médico que circula na sociedade, por meio da mídia e de outros canais comunicativos, subjetivam o educador e orientam sua prática pedagógica?

O estudo, além de ter como um dos focos a compreensão de como o discurso médico influencia o discurso pedagógico e, por conseguinte, as práticas docentes, analisa também e, principalmente, a interlocução entre equipe de saúde (reabilitação) e educadores na construção de estratégias para o ensino da criança com paralisia cerebral. Investigou-se como o discurso médico produzido pela equipe de saúde e o seu saber dialogam com os saberes pedagógicos e influenciam na reformulação de práticas pedagógicas dos professores e, por conseguinte, na inclusão dessas crianças e na qualidade do seu processo de ensino-aprendizagem.

\section{Revisitando o fracasso escolar}

Falar sobre fracasso escolar tem sido algo complexo e, às vezes, de difícil conceituação. Isso se deve ao fato das múltiplas facetas que ele possui e das diferentes possibilidades de explicações que podem surgir, em função do referencial adotado.

É preciso, primeiramente, compreender, conforme Pessoti (1984), que data da antiguidade a exclusão de pessoas com deficiência física. Para o autor, na antiguidade era comum a eliminação ou o abandono de pessoas que desviassem de um determinado padrão físico e mental, socialmente aceitos. Estavam englobadas nesse grupo as pessoas com deficiência 
física, cognitiva, com quaisquer características que implicassem na dependência econômica ou na incapacidade para o trabalho.

Patto (1999), em um estudo sobre o fracasso escolar, revela que no início do século XX surge a produção de estudos relacionados à medicina social. Esses estudos, que influenciaram a educação, se deram tanto na vertente comportamentalista como na neuropsiquiátrica, com influência da Psicanálise (SOUZA, 1998). Segundo a autora, desses trabalhos e diálogos entre os campos de conhecimento nasceram explicações decisivas para o insucesso escolar e o seu tratamento. $\mathrm{O}$ trabalho desenvolvido pelos médico-psicólogos (PATTO, 1999) chegou às clínicas de orientação infantil e às secretarias de Educação.

A entrada dos médicos e dos psicólogos na Educação e, particularmente, nas escolas, traz para essa área possibilidades de explicar o não aprender de algumas crianças, com base na vertente biológica. De acordo com Moysés e Collares, (1992, p. 31): "pode-se constatar, assim, a concretização no cotidiano da sala de aula do processo de 'biologização' das questões sociais (no caso, educacionais), processo este de cunho ideológico inegável”.

Para as autoras, embora os professores não tenham claro o significado do discurso médico sobre distúrbios de aprendizagem, seus critérios e seus usos, eles o utilizam com o propósito de se referirem a uma doença e a um problema que se encontra localizado no aprendiz. Temse visto que, ao longo de séculos, os saberes de determinadas áreas do conhecimento adquiriram força de lei, entre esses aqueles relacionados à Medicina. Tratamos aqui como discurso médico, o discurso organizado por essa instituição, mais especificamente a partir do surgimento da Medicina moderna, quando, no final do século XVIII e início do século XIX, juntamente com o surgimento da anatomia patológica, os médicos passam a organizar o discurso sobre a manifestação da doença no corpo do homem. Assim, no presente trabalho, discurso médico significa todo discurso produzido pela instituição médica e caracterizado por normas, regras, poder e saber ${ }^{4}$, capaz de subjetivar o pensamento cotidiano.

4 “Um saber é aquilo de que podemos falar em uma prática discursiva que se encontra assim especificada: o domínio constituído pelos diferentes objetos que irão adquirir ou não um status científico [...] é o conjunto das condutas, das singularidades, dos desvios [...] é também o espaço em que o sujeito pode tomar posição para falar dos objetos de que se ocupa em seu discurso" (FOUCAULT, 2000, p. 206). 
Traz no seu bojo o "conjunto das funções de observação, interrogação, decifração, registro, decisão, que podem ser exercidas pelo sujeito do discurso médico" (FOUCAULT, 2000, p. 206).

\section{Paralisia cerebral e o processo de inclusão}

Para que a inclusão educacional de fato aconteça, é necessária a reorganização do pensamento e do funcionamento social e escolar. Podemos dizer que, no caso da paralisia cerebral, conforme Rossi (1999), a concepção de educação das crianças tem passado por importantes modificações conceituais nas últimas décadas. Historicamente, o lugar dado à criança com paralisia cerebral foi a escola especial. A entrada delas na escola regular tem provocado reações diferenciadas, múltiplas interpretações e, às vezes, práticas pouco pedagógicas.

$\mathrm{Na}$ escola, as reações são bastante diversificadas, desde uma aceitação mais emotiva, cheia de pena e de sentimentos meio "melados" e superficiais que não devem durar muito ou serão prejudiciais ao desenvolvimento do aluno, até uma rejeição formal: "não temos condições nessa escola"; "Ele não vai acompanhar"; "Volte quando ele tirar a fralda" (só que ele é portador de uma mielomeningocele ou de uma paralisia cerebral grave, e não vai poder tirá-la, mas ninguém sabe disso na escola, nem cogita perguntar, informar-se). (MOURA, 2004, p. 400).

A falta de conhecimento, preparo e formação dos profissionais da educação contribui para o reforço da exclusão. Além disso, o que sabem sobre paralisia cerebral, muitas vezes, pertence ao campo do senso comum. Esse saber, fruto de um discurso socialmente produzido, costuma resultar na estigmatização e rotulação dos aprendizes.

O desconhecimento dos educadores sobre o diagnóstico da criança com paralisia cerebral e suas repercussões no desenvolvimento neuropsicomotor contribui em muito para reforçar o quadro de estigmatização social atual. Muitas confusões são feitas quanto aos diagnósticos. A mais comum delas é atribuir à criança com paralisia cerebral, com comprometimentos motores severos e comprometimentos de fala, por exemplo, a incapacidade cognitiva.

Muitas pesquisas demonstram que as crianças com paralisia cerebral, 
além do déficit motor, apresentam outros déficits associados, como, por exemplo, visual, auditivo, de linguagem, de fala, visuoespaciais, entre outros. No entanto, para definir se uma criança aprende ou não, é necessária a utilização de instrumentos que sejam capazes de medir o seu potencial cognitivo. Para isso, podem ser utilizados instrumentos formais de avaliação tanto qualitativos quanto quantitativos. É importante ressaltar que eles devem ser adequados aos objetivos e metas a serem atingidas, bem como adaptados às necessidades dos avaliados. Nesse sentido, inferimos que as escolas se encontram em condições precárias para avaliar. Além da falta de conhecimento dos docentes na área neuropsicológica, faltam à escola instrumentos adequados de avaliação.

Outro aspecto segregador no contexto escolar, de acordo com Moura (2004), é o modelo educacional competitivo. Crianças com comprometimentos motores importantes nem sempre são bem-vindas a grupos de trabalho em sala de aula. A impressão que se tem é que o cognitivo somente se desenvolve se o motor funciona bem. Nesses casos, as aparências costumam enganar. Muitas dessas crianças costumam ter um desenvolvimento cognitivo compatível com sua faixa etária, uma ótima compreensão que os habilita a participar ativamente de diferentes contextos sociais, ressalvando as dificuldades motoras que exigirão uma maior atenção.

Nesse sentido, o estudo de Braga (1995) pode contribuir para que possamos melhor compreender o processo de cognição e ação motora. A autora traz questionamentos e reflexões importantes sobre ação, manipulação de objetos e cognição. Em sua abordagem sobre a teoria piagetiana, Braga (1995) discute a relação direta entre as experiências sensório-motoras e o desenvolvimento cognitivo normal. Conforme a autora, a teoria de Piaget admite que as estruturas cognitivas se desenvolvam em estágios que dependem da estruturação de estágios anteriores, alcançados pela experiência com a ação direta sobre o objeto. Nesse sentido, estariam prejudicados, em seu processo de desenvolvimento cognitivo, indivíduos com comprometimentos motores que tivessem experiências sensório-motoras limitadas.

Esse pensamento também é reforçado pela autora ao abordar as 
teorias de Leontiev e Zporozhets. Ela comenta que, embora esses autores considerem que o processamento mental inicia-se a partir de estímulos externos, eles consideram que os "processos perceptivos e cognitivos são relacionados diretamente com os movimentos" (YOUNG, 1991 apud BRAGA, 1995, p. 153), o que implica manipulação direta do objeto pela criança para o desenvolvimento da percepção e da representação do mesmo (BRAGA, 1995).

Dessa forma, a autora indaga acerca do significado de agir sobre o objeto. Se tal ação envolve o contato táctil ou motor, acredita-se que as teorias mencionadas não são capazes de explicarem o desenvolvimento de crianças com comprometimentos motores, como, por exemplo, crianças com coreoatetose. Porém, conforme as teorias de Von Cranach e Valach, essa ação pode ser pensada em outra perspectiva. De acordo com Braga (1995), esse autores, ao analisarem o desenvolvimento da criança e considerarem os pressupostos piagetianos, construíram uma teoria com seis postulados importantes e consideram que o conceito de ação não está diretamente relacionado ao contato motor e táctil. Nesse caso,

As crianças com formas graves de paralisia cerebral e movimentos involuntários não têm condições de agir motora e tactilmente sobre o objeto mas, a princípio, não estão limitadas em relação ao planejamento ou intenção de ação, ao controle cognitivo, à representação consciente, à atenção, ao afeto, à motivação e à relação social . (BRAGA, 1995, p. 55).

Seguindo essa linha de pensamento e, considerando que a ação depende do pré-estabelecimento de um planejamento que deve ser elaborado e ajustado a contextos sociais e que acontece em situações interacionais, a autora levanta a hipótese de que as crianças coreoatetoides possam desenvolver suas ações mediadas por terceiros.

Desta forma, retomando as discussões anteriores sobre a segregação de crianças com comprometimento motor, podemos pensar que na sala de aula muitas delas deixam de participar de atividades devido aos seus limites motores. Os educadores, seja por desconhecimento teórico ou por inexperiência prática, costumam reproduzir modelos e elaborar ações pedagógicas que não contribuem para o processo de inclusão de crianças deficientes. Nesse caso, o aspecto motor acaba 
por se sobrepor ao possível potencial cognitivo, que muitas vezes não é devidamente estimulado, ficando a criança apenas por ocupar um espaço cativo na sala de aula.

\section{Método}

\subsection{Modelo de investigação}

O estudo realizado adotou uma abordagem qualitativa. De acordo com Santos Filho (1995), a pesquisa qualitativa privilegia o entendimento da verdade como relativa e subjetiva e o entendimento da realidade como socialmente construída, compreendendo o homem como sujeito e ator dessa construção, que é produto da interação.

\subsection{Participantes}

A definição dos participantes foi feita em duas etapas. Na primeira, selecionamos pacientes atendidos na Rede Sarah de Hospitais de Reabilitação (unidade de Belém-PA) na ocasião do início de suas atividades naquela cidade. A seleção da amostra se orientou pelos seguintes critérios:

a) crianças com paralisia cerebral, independente da classificação topográfica;

b) a criança deveria estar inserida no processo de escolarização, independente de estar em escola pública ou particular;

c) crianças na faixa etária entre 6 e 12 anos de idade;

d) escola localizada em Belém-PA e Região Metropolitana.

Após seguir tais critérios, chegou-se a uma amostra de 16 crianças. $\mathrm{O}$ próximo passo foi o de estabelecer contatos com as famílias e propor a participação na pesquisa. Nove famílias concordaram com a participação. Em seguida, foram contatados os profissionais das escolas, em que as crianças encontravam-se matriculadas, chegando assim ao número de oito instituições participantes.

A próxima etapa constou da seleção dos docentes. Os educadores 
selecionados estavam de alguma forma, direta ou indiretamente, ligados ao processo de ensino-aprendizagem das crianças. Eles eram professores e coordenadores pedagógicos que elaboraram tanto o programa de ensino da instituição escolar, como construíram as práticas pedagógicas cotidianas da escola.

\section{Procedimentos de coletas de dados ${ }^{5}$}

Foram realizadas entrevistas semiestruturadas com o objetivo de compreender os conhecimentos dos educadores acerca dos conceitos de paralisia cerebral, inclusão e práticas pedagógicas para o ensino da criança com paralisia cerebral. Elas aconteceram em dois momentos, início do ano letivo e final do mesmo período. No intervalo entre as entrevistas, foram realizadas visitas escolares pela equipe de reabilitação da Rede Sarah de Hospitais (pedagogo, terapeuta ocupacional, fisioterapeuta, fonoaudiólogo, psicólogo, entre outros), para acompanhamento escolar da criança . A entrevista inicial aconteceu nos dois primeiros meses de aula. O principal critério para a realização dessas entrevistas foi não ter havido contato prévio entre a equipe da Rede Sarah e os profissionais das escolas, como forma de garantir a isenção do processo.

Posteriormente, às entrevistas iniciais foram realizadas as visitas escolares periódicas com intervalos de aproximadamente dois meses. Elas tinham por objetivo dialogar com os educadores sobre o diagnóstico da criança, seus potenciais e limites, adaptações que favorecessem o processo de inclusão e de aprendizagem, a partir do acompanhamento clínico desses sujeitos realizado pela equipe de reabilitação.

Ao final do ano letivo, foram realizadas novas entrevistas com os educadores, seguindo o mesmo roteiro das entrevistas iniciais. Nesse segundo momento, buscou-se identificar os resultados advindos das interlocuções promovidas por meio das visitas da equipe da Rede Sarah ao longo do período suprarreferido.

5 Pesquisa aprovada pelo Comitê de Ética em Pesquisa - COEP - da UFMG pelo parecer no. ETIC 678/08. 6 Uma das particularidades do programa de reabilitação da Rede Sarah diz respeito às visitas escolares como forma de acompanhar o processo de inserção, reinserção e inclusão escolar, bem como dialogar com os educadores sobre estratégias de aprendizagem, acessibilidade e outros que favoreçam esta inserção. 


\section{Resultado e discussão}

\subsection{Interlocução entre Saúde e Educação: saberes movimentando a prática}

A interlocução entre Saúde e Educação terá como referência os dados gerados nos prontuários das crianças a partir do contato, discurso e diálogos produzidos na interação entre as equipes dessa duas áreas. Optamos por, inicialmente, condensar algumas informações em um quadro ilustrativo. Identificamos alguns aspectos que entendemos fundamentais para o processo e que refletem os objetivos deste estudo, e os organizamos em categorias, explicitadas no quadro. Com ele, pretendemos evidenciar, de maneira sintética, como aconteceram as visitas escolares, os aspectos abordados, as observações, intervenções e resultados. Em seguida, enfocaremos a análise qualitativa, que melhor explicitará esses aspectos sintéticos.

$\mathrm{O}$ quadro encontra-se dividido em seis partes que buscam refletir o processo e a evolução da interlocução entre os profissionais da saúde e da educação. A primeira parte consta do nome da criança e da classificação topográfica da paralisia cerebral. Optamos por apresentar a classificação topográfica como forma de possibilitar a melhor compreensão de alguns aspectos constantes no quadro, como o diagnostico e as ações pedagógicas.

A segunda parte denominamos de "Aprendizagem (percepções dos educadores)". Nesse espaço são apresentados alguns aspectos relacionados às percepções iniciais que os educadores evidenciaram sobre as dificuldades, limites e potenciais de cada criança, coletados anteriormente à visita dos profissionais da Rede Sarah às escolas.

Na terceira parte, "Aprendizagem (ações dos educadores)", evidenciamos os aspectos relacionados ao fazer pedagógico dos educadores. A partir das suas observações, cada profissional da educação apresentou tipos de ação pedagógica objetivando a aprendizagem da 
criança. Ressaltamos que elas também estão relacionadas ao primeiro contato entre as equipes. As percepções e ações que aconteceram após o primeiro contato fazem parte de outro momento que também compõe o quadro sintético.

Após apresentarmos as percepções e ações, optamos por evidenciar aspectos da interlocução. Nessa parte, a equipe da Rede Sarah esclareceu sobre o diagnóstico, suas sequelas, tipo de classificação topográfica, aspectos funcionais, limites e potenciais de cada criança.

$\mathrm{Na}$ quinta parte, aparecem algumas sugestões de estratégias que podem ser adotadas no cotidiano escolar e que influenciam no processo de participação e aprendizagem da criança com paralisia cerebral. Essas sugestões foram discutidas com os educadores após o esclarecimento do diagnóstico, tendo-o como base, além de considerar o prognóstico, o potencial e a funcionalidade inerente ao desenvolvimento de cada criança.

Por fim, retornamos ao aspecto da aprendizagem. Chamamos essa parte de "Aprendizagem, percepções e ações: resultados". Nela abordamos as reelaborações da prática pedagógica dos educadores. Procuramos evidenciar as percepções modificadas ou não, a partir do processo de interlocução e, por conseguinte, as ações pedagógicas realizadas no cotidiano escolar. 


\section{Quadro 1- Síntese sobre a evolução das visitas escolares e a interlocução entre profissionais da Saúde e da Educação}

\begin{tabular}{|c|c|c|}
\hline 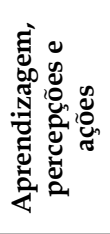 & 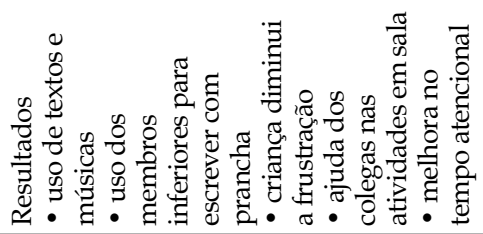 & 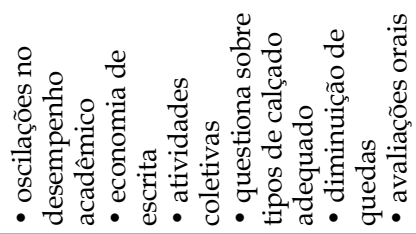 \\
\hline 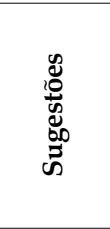 & 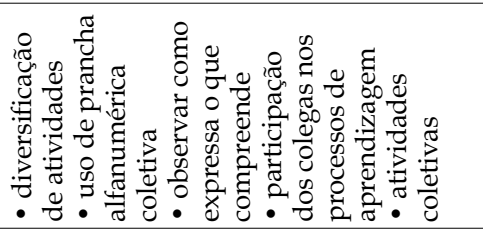 & 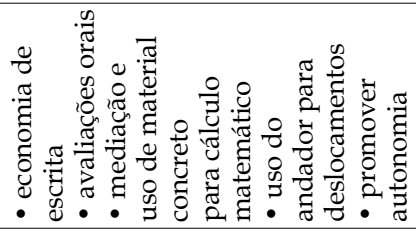 \\
\hline 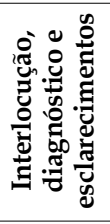 & 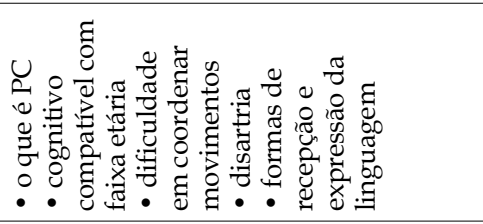 & 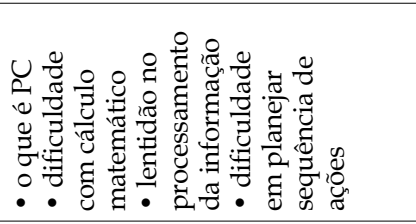 \\
\hline 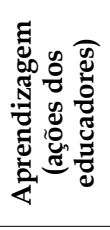 & 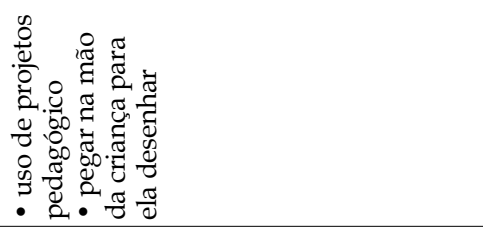 & 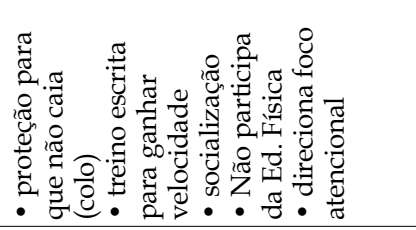 \\
\hline 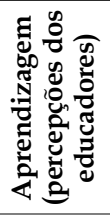 & 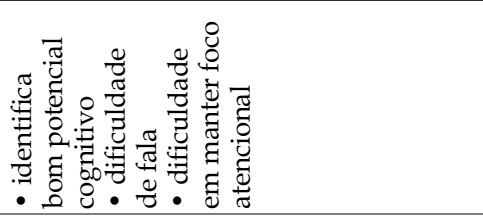 & 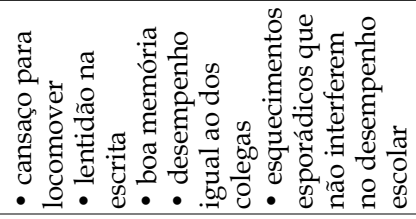 \\
\hline 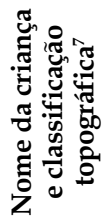 & 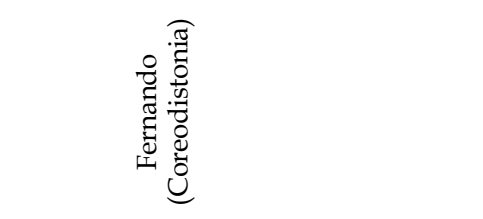 & 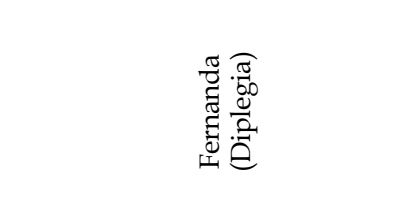 \\
\hline
\end{tabular}

7 As classificações da paralisia cerebral podem se diferenciar pelo tipo que envolve aspectos relacionados ao tônus muscular, à distribuição do acometimento no corpo, ao grau de independência motora, como também pela topografia, que tem a ver com a localização do comprometimento motor no corpo (Hemiplegia, Diplegia, Tetraplegia). A hemiplegia pode ser evidenciada pelo comprometimento de apenas um dos lados do corpo (esquerdo ou direito), sendo mais comum em membros superiores, porém pode afetar tanto membros inferiores quanto superiores, concomitantemente. A diplegia é caracterizada pelo comprometimento dos membros inferiores do corpo. A tetraplegia envolve o comprometimento dos membros inferiores e superiores concomitantemente. A coreodistonia caracteriza-se pela incoordenação do tônus muscular, movimentos involuntários e descoordenados, acometendo membros inferiores e superiores. 
Quadro 1 - Síntese sobre a evolução das visitas escolares e a interlocução entre profissionais da Saúde e da Educação

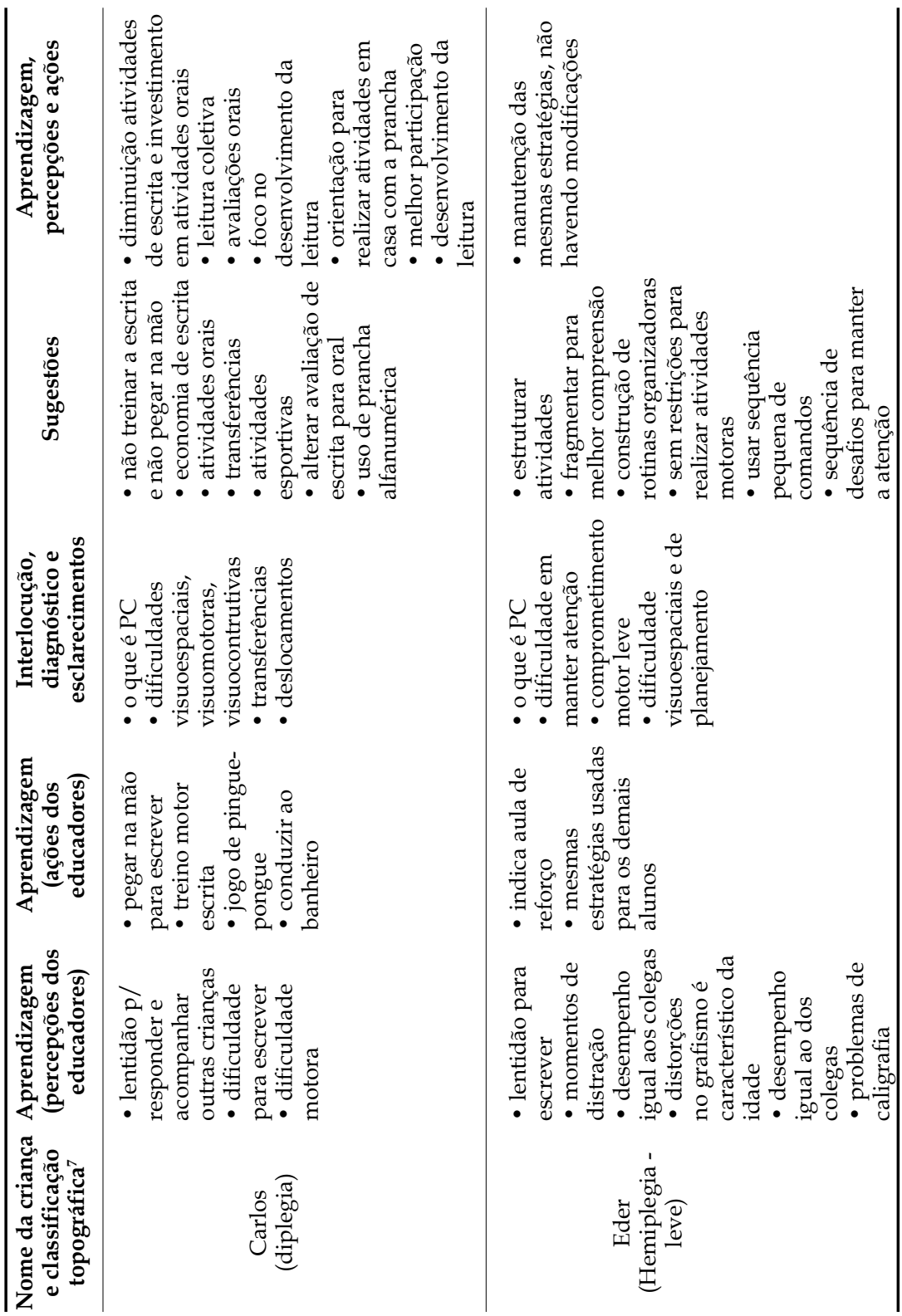


Quadro 1 - Síntese sobre a evolução das visitas escolares e a interlocução entre profissionais da Saúde e da Educação

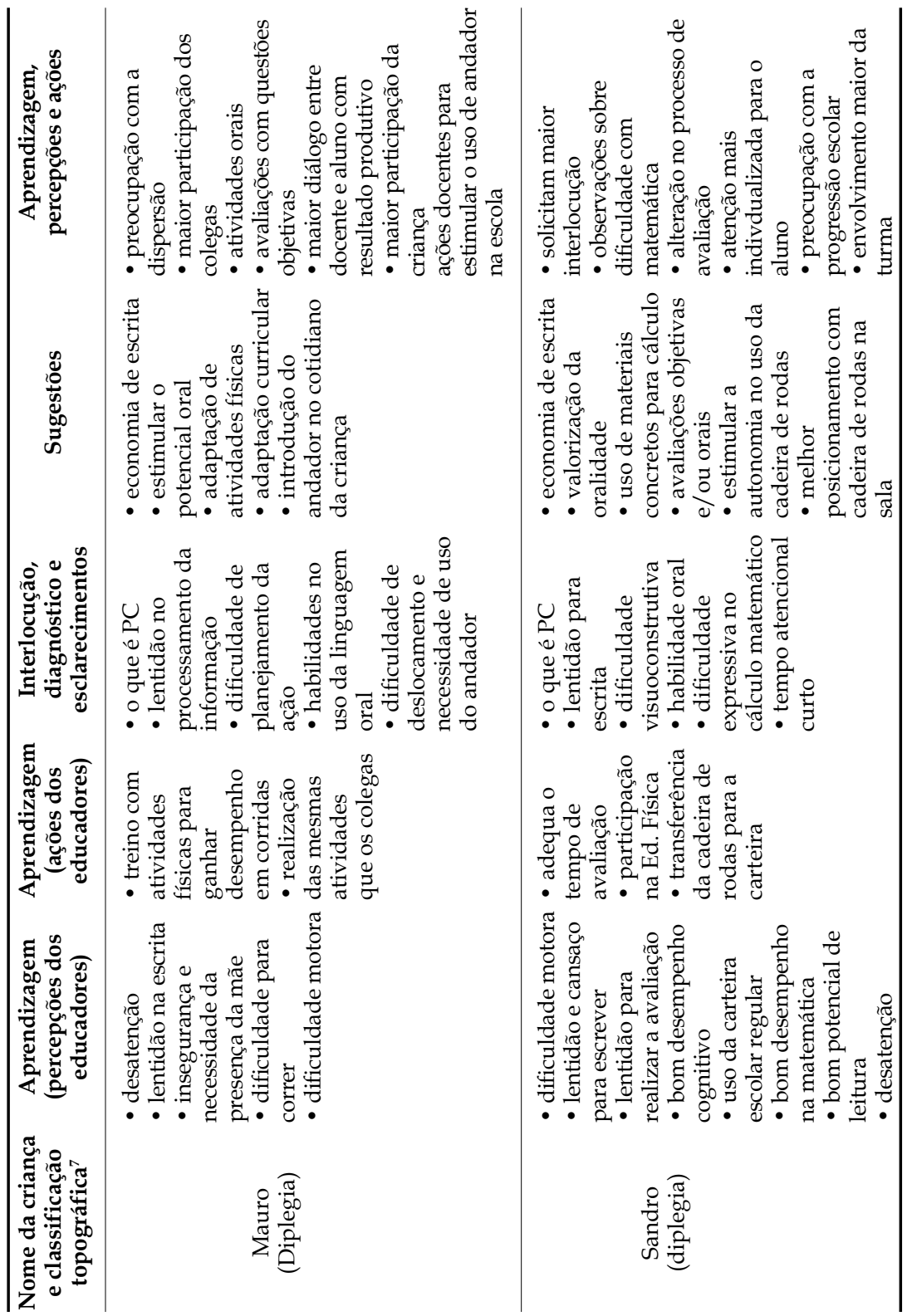


Quadro 1 - Síntese sobre a evolução das visitas escolares e a interlocução entre profissionais da Saúde e da Educação

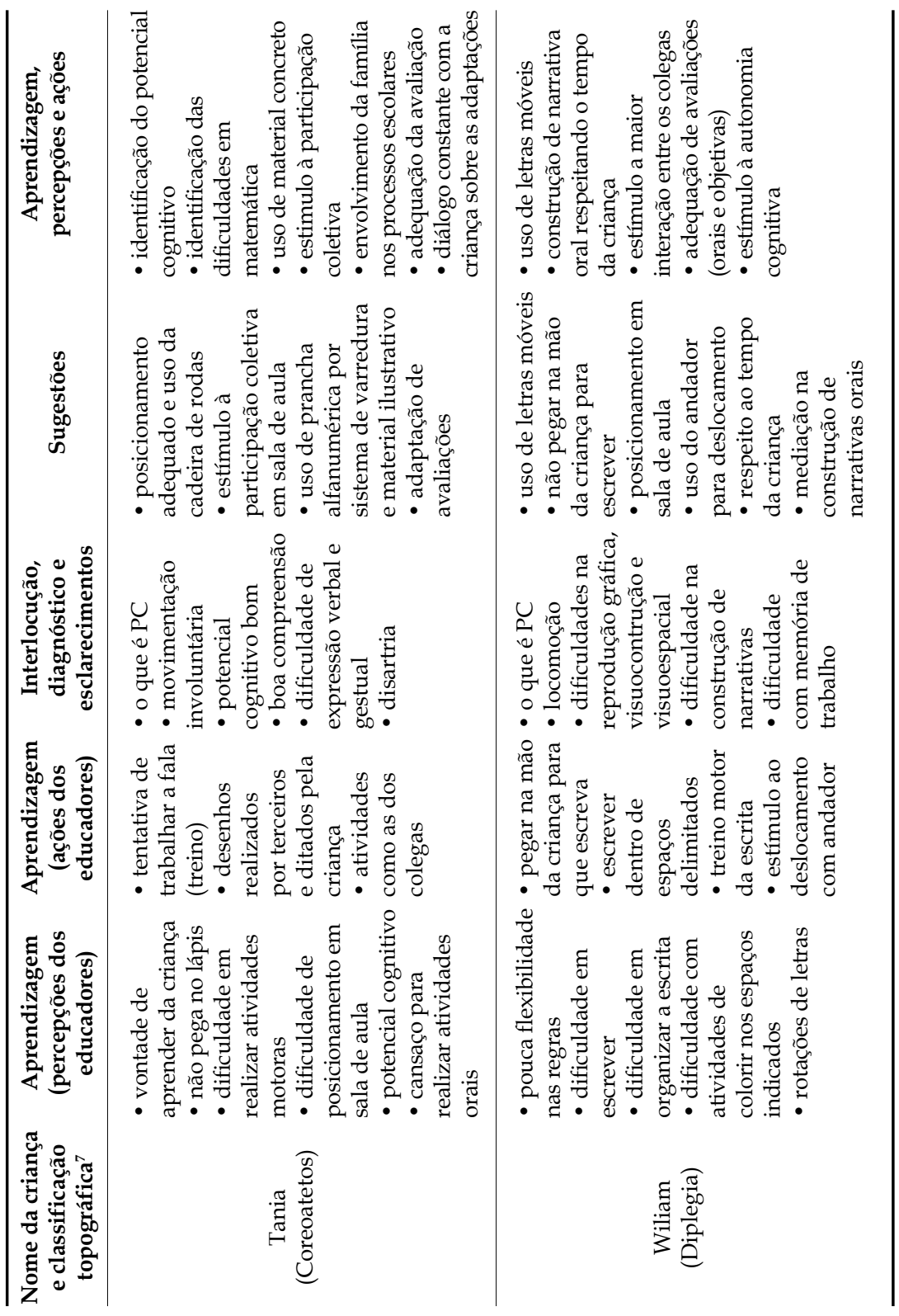


A partir dos aspectos gerais sintetizados e apresentados no Quadro 1 , podemos definir três contextos importantes que se constituem e constituem o diálogo entre os profissionais da saúde e da educação. No primeiro momento, temos a realização das visitas e a exposição verbal dos educadores sobre as suas concepções a respeito do diagnóstico, as suas percepções das dificuldades e habilidades das crianças e as suas ações pedagógicas. O segundo momento refere-se à produção de discursos e à interlocução entre campos de saberes diferentes, que acontece ao longo de todo o processo das visitas escolares e, por fim, as percepções e ações docentes reelaboradas.

Tomando o primeiro momento para análise, podemos identificar que a percepção dos educadores sobre os limites e as possibilidades de desempenho acadêmico das crianças tem como foco o aspecto motor. É praticamente unânime, por parte dos docentes, a preocupação com o desempenho grafomotor. A concepção de escrita evidenciada pelos educadores está focada na habilidade motora para colocar no papel as letras do alfabeto. Assim, como os demais colegas de sala, a criança PC deveria aprender a ler e a escrever treinando a escrita motora.

Observamos um ritual na busca pela normalidade e uma necessidade de adaptação do sujeito ao modelo (SASSAKI, 2005). Embora não digam a origem dos fundamentos que orientam a prática pedagógica, os educadores evidenciam a crença de que o treino motor poderá garantir o desenvolvimento da capacidade de escrita. Isso também significa a adoção de um método único (FRADE, 2005), para o coletivo escolar, independente das diferenças individuais.

A dimensão coletiva, social, não se constrói pela simples somatória de indivíduos, nem se manifesta linearmente em cada um. A interação entre duas totalidades, a coletiva e a individual, ambas socialmente construídas, resulta em que cada indivíduo seja expressão da dimensão coletiva, porém transformando-a segundo suas próprias particularidades. De outro lado, a cada vez que se exprime na totalidade individual que é cada pessoa, a própria dimensão coletiva se transforma. Nem somatória, nem expressões lineares; ambas unas e indivisíveis, construindo-se e transformando-se mutuamente. (MOYSÉS, 2001, p. 45).

A construção de práticas pedagógicas que objetivam o ensino não 
pode ser isolada da aprendizagem. Nesse caso, a individualidade e as diferenças devem orientar o trabalho docente, objetivando a construção do conhecimento de maneira coletiva.

Identificamos, no processo de visitas, que a percepção docente sobre as capacidades e sobre os limites de cada criança por vezes se evidencia fundamentada. Porém, essa fundamentação pode ser, em grande parte, atribuída ao aspecto empírico do processo de ensino-aprendizagem e menos ao conhecimento teórico. As observações são construídas no cotidiano da escolarização e, a partir delas, embasado por subjetivações discursivas, social e historicamente construídas, o educador elabora suas ações. Observamos que é nas ações que se evidencia a inconsistência teórica e, por conseguinte, uma prática baseada em erros e acertos. Levantamos, então, algumas questões para reflexão, como, por exemplo, como lidar com o que não conhecemos? Cabe ao professor elaborar práticas pedagógicas consistentes e inclusivas apenas com discursos que circulam na mídia ou que superficialmente ouviram em suas formações?

Entendemos que a formação do professor é fundamental para o exercício de sua prática. Ao pegarem na mão da criança para que ela escreva, demonstram que seus saberes sobre a aquisição da escrita encontram-se focados no desempenho motor, crença justificada historicamente (PATTO, 1999; MOYSÉS, 2001; SILVEIRA BUENO, 2004; JANUZZI, 2006). Nesse caso, reproduzem modelos que já foram verdades em uma determinada época e evidenciam pouco avanço em seus conhecimentos, principalmente, para atender a um publico que demanda ações pedagógicas completamente diferentes daquelas até então desenvolvidas.

Não é possível negar que o educador elabore suas práticas por conhecimentos adquiridos ao longo de sua história pessoal. Mas, seriam esses conhecimentos consistentes o suficiente para lidar com situações adversas? Entendemos que o discurso midiático e de senso comum, muitas vezes, contribui para a elaboração de práticas pouco fundamentadas. Além disso, uma formação de qualidade duvidável ou mesmo o pouco investimento do profissional em sua formação também pode contribuir para práticas pouco consistentes. 
Nessa perspectiva, identificamos que, ao longo das visitas escolares e da interlocução entre as equipes de reabilitação e pedagógica, numa relação que envolve teoria e o contexto da prática, foi possível a construção de novos olhares sobre as crianças, seus limites e seus potenciais, e a sua participação no ambiente escolar.

Observamos também que para a equipe de reabilitação esse contato torna possível compreender, mesmo que minimamente, o universo escolar, o fazer pedagógico e o distanciamento entre as duas áreas no tocante a inclusão de crianças com paralisia cerebral. Para a equipe pedagógica, observamos a grande expectativa por acesso ao que, até o momento era desconhecido, ou seja, por um conhecimento que orientasse a ação.

Identificamos que o esclarecimento sobre o diagnóstico traz ao educador mais dúvidas sobre a sua ação pedagógica. Essas dúvidas tendem a ser positivas e conduzem a questionamentos sobre a sua ação e estratégias elaboradas até o momento. Nesse caso, apenas o esclarecimento diagnóstico não se revela suficiente para o repensar a prática pedagógica. Assim podemos incorrer no risco e no equívoco de que a transmissão discursiva poderá provocar mudanças, reforçando o seu caráter, muitas vezes, prescritivo. É importante que o conhecimento clínico venha acompanhado de aplicabilidade, ao que chamaremos de "conhecimento clínico aplicado". Além disso, observou-se que a frequência periódica de vistas, com intervalos de dois meses, contribui para a fluência do discurso. Não se trata de estreitamento de laços entre os profissionais, mas de discussão e compreensão de diagnóstico, de limites e de potenciais da criança e da construção de estratégias educacionais inclusivas.

Podemos inferir que os resultados dessa interlocução foram positivos quanto à reelaboração das práticas pedagógicas. Observamos no quadro sintético que a percepção e a adoção de estratégias pelos educadores se modificaram ao longo do processo. Aparece, então, um fazer pedagógico subjetivado por um discurso que objetiva esclarecer o diagnóstico e sugerir ações com base em conhecimentos pertinentes área da saúde, sem a pretensão da prescrição. A reelaboração pedagógica não se reduz a uma lista indicada por um determinado grupo. Ela se refaz no e pelo discurso produzido em situações interacionais (BAKHTIN, 1999). Não há nada 
obscuro ou escondido por trás do discurso. Há enunciados e relações que são colocadas em funcionamento pelo próprio discurso (Fischer, 2001).

Entendemos, assim, que as reelaborações são resultados de discursos produzidos em situações de interação. Elas não são únicas e nem padrão. São atravessadas pelos aspectos e características individuais e contextuais, modificando maneiras de perceber a realidade e de nela intervir. Alterar suas percepções e pensar a ação a partir das novas leituras que se faz da realidade indica movimento. Movimento realizado por aquilo que subjetiva, que toca o sujeito. As práticas pedagógicas foram construídas pelo significado que cada docente atribuiu ao discurso ouvido e do qual participou como interlocutor. Não nos cabe aqui questionar a duração dessas práticas, mas sim evidenciar resultados de interlocuções, de práticas discursivas, produzindo sujeitos em contextos sociais, culturais e históricos. Também não nos cabe julgar se as ações foram positivas ou negativas, ou mesmo quanto ao conteúdo das mesmas. Cabe dizer que as práticas discursivas subjetivam e produzem sujeitos em contextos sociais de produção e uso do discurso. As palavras não mais nomeiam, produzem significados.

\section{Considerações finais}

Observamos que, quando dois ou mais campos de saber estabelecem uma interlocução, tendo como foco um objeto comum a eles, os resultados podem ser produtivos. Não há um resultado uniforme, e sim significados atribuídos aos discursos ou mesmo resultados de práticas discursivas. Não há um controle prévio do significado a ser produzido, do que será ou não subjetivado pelo sujeito.

Nesse caso, entendemos que as práticas pedagógicas que emergiram a partir da interlocução entre as equipes tiveram efeito positivo no processo de ensino-aprendizagem da criança com paralisia cerebral. Como exemplo, podemos considerar as alterações nos modelos e formas de avaliar com adoção de práticas de avaliação oral para as crianças oralizadas e provas objetivas para crianças que leem, mas não escrevem; economia de escrita para crianças que escrevem, porém são lentas e possuem dificuldades 
motoras; a inclusão em atividades recreativas e esportivas; a atenção mais individualizada; o envolvimento dos colegas de turma no processo de escolarização da criança, entre outros, Essa constatação nos traz questões importantes para reflexão acerca da interlocução entre campos de conhecimentos, no caso, entre saúde e educação.

Se é secular a relação médico-pedagógica, como nos afirmam Patto (1999), Silveira Bueno (2004) e Januzzi (2006), e se ao longo do tempo ela pode ter servido de instrumento de segregação e ainda o serve, como podemos observar nos estudos de Moysés e Collares (1992) e Moysés (2001), essa relação, segundo o estudo aqui produzido, também pode ser produtiva. $\mathrm{O}$ mesmo discurso que serve para justificar o não aprender de crianças com algum distúrbio ou deficiência, pode também servir para orientar a construção de ações pedagógicas que conduzam a aprendizagem. 


\section{Referências}

BAKHTIN, M. Marxismo e filosofia da linguagem. 9. ed. Tradução de M. Lahud e Y. F. Vieira. São Paulo: Hucitec, 1999.

BRAGA, L. W. Cognição e paralisia cerebral: Piaget e Vygotsky em questão: Salvador: Sarah Letras, 1995.

FISCHER, R. M. B. Foucault e a análise do discurso em educação. Caderno de Pesquisa, São Paulo, n. 114, p. 197-223, nov. 2001.

FRADE, I. C. A. da S. Métodos e didáticas de alfabetização: história, características e modos de fazer de professores. Belo Horizonte: Ceale/FAE/UFMG, 2005.

JANUZZI, G. S. de M. A educação do deficiente no Brasil: dos primórdios ao início do século XXI. 2. ed. Campinas, SP: Autores Associados, 2006.

FOUCAULT, M. Microfísica do poder. Tradução de Roberto Machado. 15. ed. Rio de Janeiro: Graal, 2000.

MOURA, M. J. Inclusão e escolaridade. In: LIMA, C. L. F. A.; FONSECA, L. F. (Org.). Paralisia cerebral. Rio de Janeiro: Ed. Guanabara Koogan, 2004, p. 399-411.

MOYSÉS, M. A. A. A institucionalização invisível: crianças que não aprendem na escola. Campinas, SP: Mercado de Letras, 2001.

MOYSÉS, M. A. A.; COLLARES, C. A. L. A história não contada dos distúrbios de aprendizagem. Caderno Cedes, Campinas, n. 28, p. 33-56, 1992.

PATTO, M. H. S. A produção do fracasso escolar: histórias de submissão 
e rebeldia. 2. ed. São Paulo: Casa do Psicólogo, 1999.

PESSOTI, I. Deficiência mental: da superstição à ciência. São Paulo: T. A. Queiroz, 1984. (Biblioteca de Psicologia e Psicanálise, v. 4).

ROSSI, L.S.P.A. Os caminhos e descaminhos da educação da criança com paralisia cerebral: pais - crianças - professores. 1999. 108f. Dissertação (Mestrado em Reabilitação) - Centro Sarah de Formação e Pesquisa, Brasília, 1999.

SANTOS FILHO, J. C.; GAMBOA, S. S. (Orgs.) Pesquisa educacional: quantidade-qualidade. São Paulo: Cortez, 1995.

SASSAKI, R. Inclusão: o paradigma do século 21. Revista Educação Especial, Brasília, v. 1, n. 1, p. 19-23, out. 2005.

SILVEIRA BUENO, J. G. Educação especial brasileira: integração/ segregação do aluno diferente. 2. ed. São Paulo: EDUC, 2004.

SOUZA, L. M. N. Estimativa de desempenho de crianças e adolescentes com paralisia cerebral. 1996. 99f. Dissertação (Mestrado em Psicologia ) Programa de Pós-Graduação em Psicologia, Universidade de Brasília, Brasília, 1996.

Recebido em 13/07/2013 Aprovado em 06/04/2014 